\title{
UMA LINGUAGEM MARGINAL EM BUSCA DE RECONHECIMENTO: a música rap e a integração sociocultural dos jovens periféricos
}

Rafael Lopes de SOUSA ${ }^{1}$

Álvaro Cardoso GOMES ${ }^{2}$

Márcia Aparecida LEÃO 3

\author{
${ }^{1}$ Doutor em História Social (UNICAMP) e Professor do Mestrado Interdisciplinar em Ciências Humanas \\ da Universidade de Santo Amaro (UNISA). E-mail: canoeiros2008@gmail.com \\ ${ }^{2}$ Professor Titular da USP e Coordenador do Mestrado Interdisciplinar da UNISA. \\ E-mail: acgomes@unisa.br \\ ${ }^{3}$ Mestre em Educação. E-mail: acgrellet@ibest.com.br
}

Recebido em: 29/07/2015 - Aprovado em: 22/11/2015 - Disponibilizado em: 22/11/2015

\begin{abstract}
Resumo
Este artigo oferece pistas para entender o cotidiano da população jovem da periferia que vive marginalizada nas grandes cidades. A análise problematiza o caráter simbólico ou estratégico que a música desempenha na existência dos jovens, considerando as possibilidades ou não de a sociedade brasileira correr o risco de viver novas experiências e formulações de cidadania que a agenda da "marginalidade juvenil" trouxe para pensar algumas questões do Brasil contemporâneo. Considerando tal perspectiva, investigará os aspectos formais das crônicas musicais dos rappers, em que o vocabulário, as imagens, o ritmo, criam um dialeto específico que se contrapõe à norma culta, como forma de protesto, de defesa contra a opressão da cultura hegemônica.

Palavras-chave: rap. crônica musical. Periferia. jovens.
\end{abstract}

\begin{abstract}
This article aims to study the daily life of young people from the periphery who lives marginalized in the big cities. The analysis discusses the symbolic or strategic role that music plays in the existence of young people, considering the possibilities or not of Brazilian society to risk new experiences and citizenship formulations that the agenda of "juvenile delinquency" brought to think some questions of contemporary Brazil. Given this perspective, investigate the formal aspects of musical chronicles of rappers in the vocabulary, images, rhythm, create a specific dialect that is opposed to cultural norms, in protest of defense against the oppression of the hegemonic culture.
\end{abstract}

Keywords: rap. musical chronic. Periphery. young people.

\section{INTRODUÇÃO}

Uma das possibilidades de se compreender a vivência juvenil na periferia de São Paulo da década de 1990 para cá passa, necessariamente, pelo percurso desenvolvido pela cultura hip hop nessas localidades. Seus agentes e suas práticas representam um segmento crítico que insiste em levantar a voz contra as precariedades das condições de vida de suas regiões. Essa postura crítica produziu dois efeitos simbolicamente importantes para o movimento rap: primeiro, assistiu-se a uma renovação do interesse dos jovens 
periféricos em conhecer melhor a história de seus bairros, nascendo daí uma consciência comprometida e engajada com o cotidiano ao qual se encontram ligados; num segundo momento, verifica-se um maior empenho na construção de alternativas de convívio social além das convencionalmente pensadas e imaginadas para suas vidas.

Como foi construída essa identidade coletiva? Como se consolidou essa confiança depositada pelos jovens periféricos no rap? Como o rap conseguiu acumular e organizar forças para pensar a história dos negros de outra perspectiva? Quais elementos afetivos e identitários contribuíram para o nascimento dessa empatia entre o rap e a periferia?

Uma tentativa de resposta a essas indagações passa pela historicização das tradições de luta e resistência protagonizadas pelos descendentes africanos no continente americano, notadamente nos EUA e no Brasil. Ainda que preservadas certas especificidades, é possível entrever algumas similitudes nas práticas de resistência dos afrodescendentes do Norte e do Sul do continente americano. Essas semelhanças são, aliás, responsáveis pelo rompimento das fronteiras territoriais e das barreiras linguísticas, promovendo um inédito encontro de interesses que culminou no desenvolvimento de diversas manifestações artísticas e culturais, sendo que na atualidade o rap tem postulado um lugar de destaque nestas manifestações.

\section{AS TRADIÇÕES DE LUTA E RESISTÊNCIA DA CULTURA NEGRA}

O rap é o herdeiro redivivo de uma tradição da cultura de luta e resistência que se propagou para o mundo a partir da diáspora africana. Do final do século XVIII ao alvorecer do século $\mathrm{XX}$, a música dos afrodescendentes tem sido utilizada como um importante elemento aglutinador da cultura negro-mestiça nas Américas. Ela difundiu hábitos, preservou tradições e consolidou costumes. Dos work songs ao spirituals, do blues ao jazz, do soul ao funk, do samba ao rap, em maior ou menor escala, cada um desses estilos musicais constituiu uma base de resistência às hostilidades que os negros sofreram longe de suas terras natais.

Essa estratégia de usar a música como veículo de comunicação e interlocução sociocultural não foi 
obviamente inventada pelos rappers. Eles apenas potencializaram essa vertente artística valorizando a tradição oral de seus antepassados em suas manifestações. Contribuindo, assim, com a construção de um espaço onde os "sem palavras" e os "sem escrita" podem manifestar livre e abertamente suas opiniões para contestar, "a formação de uma cultura nacional que criou padrões de alfabetização universais e generalizou uma única língua vernacular como o meio dominante de comunicação em toda nação" (HALL, 1999: 49).

A fim de fugir dessas amarras impostas pela cultura consensual, os jovens banidos da vivência cívica inventam o break, atualizam as práticas do grafite e, ato contínuo, estabelecem novos princípios de comunicação e formação para suas vidas. Amparados, agora, pela visibilidade proporcionada pelo discurso rap e pela natureza democrática que alimenta as suas reuniões, essas novas práticas culturais, isto é, o break e o grafite ganham força e ajudam a construir novas redes de sociabilidade para os jovens periféricos.

Os rappers orgulham-se, pois, de retratar em suas crônicas musicais o cotidiano dos mutilados sociais que vivem na periferia dos grandes centros urbanos do país. Pode-se dizer, então, que a disposição de enfrentar os problemas de suas vidas de frente ofereceu condições - não planejadas para a formação de uma cultura que corria paralela à cultura consensual. Em outras palavras, ao fazer suas intervenções artísticas na arena pública, os militantes da cultura hip hop, mais do que a realização pessoal, buscam a transformação sociocultural de suas comunidades. Em busca desse ideal, os adeptos deste estilo musical, formam um grupo específico que atua em duas frentes aparentemente distintas, mas historicamente imbricadas. Numa frente trabalham para fortalecer os vínculos afetivos e identitários em suas comunidades, promovendo o resgate e a valorização da memória de seus antepassados. Em outra, elaboram códigos de pertencimento - que aproximam e criam cumplicidade entre os militantes da causa rap - com destaque para o modo de vestir: calça e jaquetas largas, tênis de cano alto com o cadarço desamarrado, adornos dourados, bonés ou bandanas.

Nesse complexo universo paralelo, outra característica chama atenção: o modo todo especial de se comunicar, por meio do qual os rappers 
criam uma linguagem codificada, um modo de se expressar específico que, por mais marginal e vulgar que possa parecer conquistou, ainda assim, a simpatia de amplos setores da classe media. Situação que é, aliás, exaltada pelos rappers em suas crônicas musicais. “[...] Inacreditável/ mas seu filho me imita/ No meio de vocês, ele é o mais esperto/ Ginga e fala gíria/ Gíria, não dialeto [...]". (Racionais MC'S "Negro Drama" do álbum Nada como um dia após o outro, de 2002).

A gíria e a moda rap caracterizam, então, uma cultura de insubordinação dos jovens periféricos que, após a redemocratização da sociedade brasileira, cultivam um permanente e contínuo distanciamento das instâncias mediadoras do "Brasil cordial", para adotar, em um mesmo movimento, um conflito aberto, generalizado e sem tréguas no espaço urbano. Assim, em que pesem as críticas e injurias que a cultura consensual faz às opções e caminhos escolhidos pelos militantes do movimento rap, é importante ressaltar que as cobranças e enfrentamentos que suas intervenções trazem para a arena pública revelam um desgaste dos princípios que sustentam o discurso do Brasil cordial, principalmente por apresentar a violência e o conflito - em lugar do acordo e do entendimento - como métodos privilegiados de comunicação e protesto.

Três fatores contribuíram decisivamente para o desenvolvimento dessa insubordinação periférica. O primeiro está relacionado com a pouca oportunidade que os jovens, principalmente os jovens suburbanos, encontraram, a partir da década de 1980, para integrarem-se no mercado de trabalho. $\mathrm{O}$ segundo fator está diretamente associado ao primeiro, ou seja, à medida que são distanciados do mundo do trabalho e das oportunidades que ele reserva, os jovens reagem e respondem, por exemplo, com o aumento do desinteresse pelos estudos e pela instituição escolar. Estabelecem, com esse posicionamento, uma relação pragmática com os estudos e com outras instâncias do conhecimento formal. Em outras palavras, a escola perde o status privilegiado de ser a principal fonte de conhecimento e oportunidades de emancipação para a vida dos jovens periféricos. Num terceiro plano, encontra-se o aumento da desconfiança 
dos pobres na imparcialidade $\mathrm{e}$ infalibilidade da Justiça.

Não se trata de fazer uma caricatura, mas de propor uma hipótese, a de que quando alguns dos principais pilares de inserção e sustentação dos jovens na vida social enfraquecem, a sociedade torna-se também frágil, pois deixa de usufruir adequadamente da energia e da criatividade desse segmento, que, ao se sentir impedido de participar da vida cívica desloca suas expectativas para um circuito fechado, pouco compreensível aos olhos e ao entendimento da sociedade.

Essa nova modalidade de reclamar, isto é, essa intervenção violenta que agora trazem para o espaço urbano está segundo Rocha (2004), presente na maioria das representações culturais do Brasil contemporâneo. Ganha importância, todavia, em expressões artísticas que retratam de maneira incomum e contundente $\mathrm{o}$ cotidiano da periferia. Para esse autor, as músicas dos Racionais MC's e os romances de Ferrez $z^{2}$ merecem destaque pela elaboração e pelas proposições apresentadas. Apesar de serem expressões artísticas manifestadamente voltadas para as causas e problemas das regiões periféricas, é importante lembrar que outros conflitos da cultura brasileira da contemporaneidade são também evidenciados nessas representações sempre de maneira aberta, franca e sem maquiagem. São essas características, aliás, que distinguem, no limite, a marginalidade de hoje da malandragem de outrora.

Pode-se dizer, então, que, ao trazer à tona os problemas permanentemente negligenciados e as reivindicações reiteradamente desprezadas pela cultura consensual, o movimento rap cria uma "poética da sobrevivência" na periferia e forja, com essa atitude, outras representações culturais para o Brasil contemporâneo. Esse movimento supera, assim, os limites estabelecidos pela "Dialética da Malandragem" e, num mesmo movimento, criam as condições favoráveis para o desenvolvimento da "Dialética da Marginalidade".

Pontuando as diferenças entre essas duas culturas, Rocha (2004) sustenta que os mecanismos de atuação da primeira oscilam sempre entre os pólos da ordem e da desordem, na busca de acordos e entendimentos com a vã ilusão de ser "absorvido pelo pólo convencionalmente positivo" da sociedade. Já os preceitos que norteiam o campo de atuação da segunda vertente, isto é, que guiam as ações da 
"Dialética da Marginalidade" não trabalham em busca da conciliação ou da harmonização social e é por isso, precisamente por isso, que seus representantes rejeitam enfaticamente qualquer tentativa de acordo ou entendimento como moeda de troca para a ascensão social.

Apresentar as contradições da nação, numa "critica certeira da desigualdade social", parece ser o principal compromisso do movimento rap. Por isso, os traços característicos e comuns que permeiam a vida dos jovens periféricos - preconceito, desemprego, exploração, perseguição e analfabetismo, violência, crime, drogas e prostituição - ganham destaque em suas crônicas musicais; divulgando o submundo de suas vidas, seus integrantes insistem, ademais, em dizer que vivem em meio a uma guerra que não foi inventada por eles e da qual são as maiores vítimas: “[...] me tiraram a paz/ quebraram a trégua/ transformaram nossa vila num campo de guerra [...]". (Detentos do rap, do álbum, Campo de Guerra, de 2002). Fazem com isso "um esforço sério de interpretação dos mecanismos de exclusão social, pela primeira vez realizado pelos próprios excluídos”. (ROCHA, 2004).
Esse despertar de consciência, em torno da sofrível condição na qual se encontram imersos empresta a esses jovens, banidos da vivência cidadã, uma conotação radical para suas manifestações. Dificultando a aceitação e, consequentemente, a participação em um jogo que tem regras e norma préestabelecidas, mas que eles não ajudaram a elaborar. Por isso, "o fato de eles começarem a recusar jogar o jogo pode ser o fato que marca o começo do fim de um período" (MARCUSE, 1982: 235).

O início da década de 1980 marca, de fato, o começo de um novo período para a sociedade brasileira. Com a abertura política, tudo se torna alvo de questionamentos e críticas. Uma nova lógica de participação cívica emerge desse cenário e, de imediato, rejeita os dois lados da moeda, isto é, rejeita os valores, princípios e determinações da cultura consensual, por um lado, enquanto, de outro, põem sob suspeição as alternativas oferecidas pelos "modelos salvacionistas" que orientaram as lutas sociais e os partidos de esquerda nas décadas de 1960 e 1970. O novo era o que se esperava, o novo era o que se buscava. Era como se tivesse iniciado o segundo tempo de um jogo, só que com novos jogadores, os 
quais não aceitam as regras estabelecidas e, por isso, resolveram impor suas condições para participar do teatro social.

$$
\text { É neste cenário em }
$$

transformação que os elementos constitutivos da cultura hip hop estão sendo delineados. $O$ desafio de experimentar as possibilidades que as tecnologias eletroeletrônicas oferecem já havia sido devidamente investigado pelas gerações anteriores. A meta agora, portanto, é ampliar os horizontes oferecidos por esses recursos e é isso, precisamente isso, que o movimento rap faz ao introduzir e trabalhar novos conceitos na música urbana contemporânea.

Esses novos conceitos manifestam-se, por exemplo, no ritmo intencionalmente agressivo e na mensagem conscientemente politizada de suas crônicas musicais. Há nelas um otimismo geracional, que viabilizou uma inédita relação dos jovens periféricos com o uso e as possibilidades de uso dos espaços urbanos da nação a parti da década de 1980. Esse período corresponde a uma fase de transição onde os projetos, anseios e expectativas do indivíduo foram postos à prova diante da nova conjuntura vivenciada pelo país. A abertura política, as eleições diretas para Governador a partir de 1982, a campanha pelas Diretas Já em 1984 e a convocação de uma Assembléia Nacional Constituinte em 1988 são eventos que sintetizam um pouco o clima desses novos tempos.

Abaixo desses projetos maiores ou, dizendo de outro modo, de envergadura nacional encontravam-se demandas consideradas até então como "menores", mas que ganharam importância na nova agenda sociopolítica da nação quando os jovens, principalmente os jovens periféricos resolveram apresentar para a sociedade uma pauta de reivindicações que orientaria e intermediaria o convívio de uma nova vida pública.

A cultura hip hop contribui com a leitura dessa nova realidade, praticando intervenções no espaço urbano e escrevendo crônicas musicais que, via de regra, denuncia o sofrimento dos negros e mestiços que vivem esquecidos nas bordas da sociedade. Assim, quando a situação pede, eles apelam à fé e à sensibilidade religiosa do indivíduo: "[...] que Deus me guarde, pois eu sei que ele não é neutro/ vigia os ricos mas ama os que vêm do gueto[...]" (Racionais MC's, do álbum, Nada como um dia após o outro dia, de 2002). Caso 
essa estratégia mostre-se insuficiente para conquistar a confiança da comunidade, eles recorrem a outro expediente de igual importância, com uma força mobilizadora ainda maior e denunciam o preconceito racial do qual são vítimas: “[...] negro drama / cabelo crespo e a pele escura/ a ferida a chaga, a procura da cura [...]" (Idem). Se ainda assim não conseguem despertar a consciência da comunidade, com nenhuma dessas estratégias, eles colocam em pauta a truculência com que a polícia costuma tratar os seus semelhantes: "[...] não confio na polícia raça do caralho/ Se eles me acham baleado na calçada/Chutam minha cara e batem em $\mathrm{mim} / \mathrm{Eu}$ sangraria até a morte/Já era um abraço/Por isso minha segurança/Eu mesmo faço [...]" (Racionais MC's, do álbum, "Raio X Brasil", de 1993).

Os fragmentos acima exemplificam bem como os rappers lidam com as dificuldades cotidianas da periferia. Para além do conformismo, da resignação, da alienação, enfim, que a cultura consensual sempre quis lhes imputar, o relacionamento que estabelecem com os conflitos da vida urbana deixa entrever uma postura militante com os problemas e riscos que o meio social lhes impõe. Isso permite que as demandas impostas por essa conjuntura adversa sejam recolhidas e cuidadosamente inventariadas em suas crônicas musicais como forma de denúncia social.

$60 \%$ dos jovens de periferia sem antecedentes criminais já sofreram violência policial. A cada quatro pessoas mortas pela polícia três são negras. Nas universidades brasileiras apenas 2\% dos alunos são negros. "A cada quatro horas um jovem negro morre violentamente em São Paulo" (RACIONAIS MC's, do álbum, Sobrevivendo no Inferno, de 1997).

As características presentes no movimento hip hop apresentam elementos que Manuel Castells (2002) chamou de construção da "identidade de projeto", cuja formação se dá a partir de um projeto cultural. Observa-se que o rap se destaca das outras artes de rua por criar possibilidades para a construção de uma identidade de resistência e que, de acordo com suas análises, alcança maior legitimidade quando é:

[...] criada por atores que se encontram em posições/condições desvalorizadas e/ou estigmatizadas pela lógica da dominação, construindo assim trincheiras de resistência e sobrevivência com base em princípios diferentes dos que permeiam as instituições da sociedade, ou mesmo opostos a estes últimos. (CASTELLS, 2002, P. 24)

\section{Aspectos Formais das}

\section{Composições}

A maioria dos representantes da cultura hip hop não frequentou a escola formal sendo, quase sempre, obrigados 
a interromper os estudos, a fim de ajudar a família na luta pela sobrevivência. O reduzido contato que mantiveram e mantém com a educação formal criou as condições para uma formação autodidata criando, por via de consequiência, uma narrativa de autoidentidade em suas crônicas musicais. Em geral, buscam na realidade, dentro do universo infindável da pobreza: orfandade, desemprego, violência e até mesmo em desilusões amorosas a inspiração para compor. Daí a dificuldade, a indisposição mesmo, da cultura hegemônica de reconhecer as crônicas musicais dos rappers uma manifestação verdadeiramente artística.

Shusterman (1998) sustenta a esse respeito que a lógica desse pensamento reducionista está associada à ideia bastante difundida de que a "classe baixa" não produz cultura nem arte. Logo, por ser uma manifestação genuinamente periférica, a cultura hip hop sofreu e sofre a rejeição generalizada da cultura hegemônica.

As raízes culturais do rap e seus primeiros adeptos pertencem à classe baixa da sociedade negra norte-americana; seu orgulho negro militante e sua temática da experiência do gueto representam uma ameaça para o status quo complacente da sociedade. Dado esse incentivo político, é fácil encontrar as razões estéticas para desacreditar o rap enquanto forma legítima de arte. (SHUSTERMAN, 1998, p. 143).
Discriminados, perseguidos e rejeitados pelas representações da cultura hegemônica, os jovens envolvidos com a cultura hip hop voltam-se com maior determinação para as causas e problemas que esgarçam as relações sociais na periferia. Com essa atitude, afastamse, de maneira resoluta, da expectativa envolvente de que um dia serão convenientemente “absorvidos pelo pólo positivo da sociedade". Ressalte-se que essa disposição de lidar de maneira mais realista com o cotidiano de suas vidas foi fortalecida pelos elementos constitutivos da cultura hip hop, pois, na medida em que divulgam os valores e sentimentos da periferia, esses jovens estabelecem, num mesmo movimento, uma relação de confiança com seus semelhantes e de altivez com os centros iluminados da cidade ou, como eles costumam dizer: com o mundo "depois da ponte". O conhecimento orgânico que tem sobre as realidades da periferia empresta realismo para as letras de suas músicas. Por isso mesmo, a formação do gosto dos compositores obedece a um princípio de imitação de modelos musicais, disseminados na comunidade 
a que pertencem. É possível identificar em todas as composições determinados elementos básicos, presentes nas letras da música popular, como o verso, a estrofe, a rima. Formalmente, as letras têm como unidades básicas os versos, entendidos como segmentos frasais com algumas características específicas.

É a sucessão de sílabas ou fonemas formando unidade rítmica e melódica, correspondente ou não a uma linha do poema. Cada verso pode compor-se de subunidades ou células métricas, caracterizadas pelo agrupamento de sílabas, chamado pé na versificação greco-latina; ou compor-se de uma sequência de sílabas ou fonemas, como de uso entre as línguas românticas. No primeiro caso, a quantidade ou duração das sílabas é que importa; no segundo, o seu número; ali temos o sistema quantitativo, aqui o silábico, qualitativo ou acentuativo. (MOISÉS, 2005, p. 508)

Mas os versos das composições dos rappers, de maneira geral, além de serem descomprometidos com uma metrificação precisa, são também quantitativamente muito longos. Essa característica pode, possivelmente, ser associada a uma falta de conhecimento da metrificação. Talvez, por isso, os jovens envolvidos com esse ritmo musical ignorem o ritmo silábico do verso e o substituam pela batida forte da música. Pode-se afirmar, então, que o cantor/compositor é movido quase que integralmente pela intuição, emoção e capacidade de improvisação. Nas letras de rap, portanto, não se pode falar em regularidade no sistema quantitativo, pois a variação de sílabas de verso para verso é muito grande.

A crônica musical "Pião da Vida Loka" é um exemplo que serve para sustentar essa nossa argumentação. Salientamos, todavia, que a natureza caudalosa dessa crônica musical inviabiliza uma analise integral de sua letra. O que queremos destacar é que neste e, em outros casos, a extensão dos versos varia ao extremo. Em alguns momentos, eles compreendem duas linhas; em outros, seis e mesmo dez, isso se se considerar os blocos de frases, limitados pelo ponto final, como um conjunto de versos (e/ou estrofe). Se não se considerar desse modo, é possível ver cada bloco, limitado pela pontuação, como um único e extensíssimo verso, cuja medida varia bastante. Outra situação: a alternância entre os blocos mais curtos e os mais longos é aleatória, não obedecendo a nenhum padrão definido. $\mathrm{O}$ caráter aleatório da arrumação dessa composição e, acima de tudo, do tamanho dos versos salienta o aspecto recitativo da composição com uma entonação mais prosaica, que mimetiza o ritmo da fala coloquial. 
Outro aspecto que chama atenção nas letras de rap é a utilização da rima como recurso nem sempre constante e que obedece a padrões dos mais variados. A rima é um recurso sonoro que tem uma função de retorno a um princípio e que, portanto, facilita não só a memorização de uma sequência, como também serve para prever a sonoridade vindoura. A rima não é garantia de poesia, senão um recurso que tanto pode servir de adjuvante num texto poético (por razões intrínsecas de ritmo e imagem), o que é mais comum, ou mesmo num texto de prosa, embora isto seja mais raro. No caso das composições, verifica-se, numa primeira instância, a presença das chamadas rimas soantes, que se caracterizam pela concordância sonora completa da última sílaba tônica das palavras:

Quero saber o porquê daquele olhar

Eu tô na dela aí, vou enquadrar

(509-E/Dexter, "Saudades Mil" do álbum Provérbios 13, de 2000)

As rimas em ar são consideradas ricas, porque a classe gramatical das palavras é diferente: "olhar", substantivo, e "enquadrar", verbo. O mesmo acontece no exemplo abaixo - a classe gramatical dos termos rimados é diferente (adjetivo, substantivo):

Ontem tudo bem com a família inteira

Hoje um a menos parece brincadeira (509-E/Dexter, "Saudades Mil" do álbum Provérbios 13, de 2000)

Em outros casos verifica-se a presença de rimas soantes no interior de um verso:

Eu tô por aqui na fé na paz, na correria adiantos (sic) e mais

Me lembro das festas que a gente fazia, saía às dez da noite e só voltava no outro dia

(509-E/Dexter, "Saudades Mil" do álbum Provérbios 13, de 2000)

Esse recurso é levado a extremo em "Pião da vida loka", talvez para quebrar a monotonia dos versos muito extensos. Para temperar o prosaico com o poético, por meio do retorno a um determinado tipo de sonoridade, o autor utiliza engenhosa repetição de um mesmo recurso: o uso da rima interna, a intervalos mais ou menos regulares: “enquadrado/forgado", "facção/capão", "escadinha/minha", "Pinheiros/maloqueiro", "fora/hora", “moral/pau”, “joga (por jogar)/fica (por ficar)/luga (por lugar)", "hora/fora" e assim por diante. 
Além das rimas soantes, os compositores usam as rimas toantes, caracterizadas pela concordância sonora somente da vogal tônica da última palavra dos versos:

nada anda bem, cada dia que passa as coisas ficam mais difíceis.

Com a Laisla tudo bem, pois ela ainda uma criança e não compreende as surpresas da vida.

Sabe meu amigo...

(509-E/Dexter, "Saudades Mil" do álbum Provérbios 13, de 2000)

A concordância rímica se dá somente na identificação sonora da sílaba tônica da última palavra (“i”). O mesmo acontece nos versos seguintes, em que se dá a identificação sonora final da tônica "a":

Natal de 97 passei na sua casa,

Muita treta vários amigos na parada

(509-E/Dexter, "Saudades Mil" do álbum Provérbios 13, de 2000)

As letras incluem também um refrão, que institui a polifonia, ou seja, as vozes que se alternam entre a voz principal, enunciadora do tema, e o coro. Essa técnica, que remonta ao teatro grego clássico, estabelece um contraponto que sugere a integração ente a voz de comando do líder e a resposta da comunidade.

A existência dos versos, das rimas, do refrão, expedientes muitas vezes utilizados pela poesia, contudo, não faz que as letras dessas músicas constituam poesia em si, o que nos leva a uma reflexão mais cuidadosa das diferenças de gênero. Em síntese, a poesia se diferencia da prosa, já numa distinção apontada por Aristóteles, não pela existência do verso (além da rima, é claro) propriamente dito. Há muitos exemplos da mais genuína poesia que não se utiliza do verso e nem mesmo da rima, como se pode verificar, por exemplo, nos poemas em prosa de um Baudelaire e de um Cruz e Sousa. Por outro lado, durante os séculos XVII e XVIII, era muito comum ver tratados científicos escritos em verso, sem que tais textos pudessem ser considerados como poéticos. Na realidade, um texto só é considerado poesia, se tiver um ritmo especial e, sobretudo, se trabalhar com a imagem, como um modo específico de traduzir o real. Para o poeta mexicano Octavio Paz, um poema

[...] é um mundo de ritmos e símbolos. Correspondência e analogia não são mais do que nome do ritmo universal (...), é o doble do universo: uma escrita secreta, um espaço coberto de hieróglifos. Escrever um poema é decifrar o universo, só para cifrá-lo novamente. (PAZ, 1982, 89 e 98). 
A imagem implica, assim, a aproximação de coisas distintas ou a sua diferenciação, num contexto sintético, o que supõe o uso sistemático das chamadas figuras retóricas, principalmente a metáfora, a analogia, a comparação, a antítese. Já o que acontece nas letras de rap é a prosa pura e simples, com o ritmo sugerido pelas rimas e, acima de tudo, pelo suporte dado à letra pela entonação, pelo acompanhamento dos instrumentos musicais, pela batida da bateria. Em suma, as letras só se sustentam quando cantadas e/ou recitadas, ou, melhor dizendo, não constituem poesia em si, não contém poesia.

Ainda do ponto de vista formal, observa-se que muitas letras seguem o modelo de prosa em forma de narrativa porque contam histórias de um povo que sofre as consequências diretas da exclusão social, num mercado com

\section{Considerações Finais}

\section{A cultura hip hop é resultado duma intensa e complexa troca de experiências culturais tramadas no submundo da sociedade pós-industrial. Ao Compartilhar horizontalmente ideias, sentimentos e estilos sem a presunção de unificar gostos ou de}

poucas oportunidades de emprego e de sobrevivência. Também há letras em forma demonstrativa, que recorrem à oratória. Algumas, como o seguinte modelo de carta inserida na letra de rap, usam uma estrutura de carta para desenvolver um tema. Essa é uma variante usada, entre outros, pelo grupo 509-E:

\section{Saudades Mil}

Diadema 2 do doze de 99.

Saudades amigo Dexter, tudo bem?

Espero que sim e que esta o encontre na mais pura paz espiritual, e que você esteja firme e forte.

Olha, por aqui nada anda bem, cada dia que passa as coisas ficam mais difíceis.

(509-E/Dexter, "Saudades Mil" do álbum Provérbios 13, de 2000)

estabelecer princípios norteadores para suas vidas, os militantes da cultura hip hop conseguiram aglutinar os jovens periféricos em torno de uma causa comum.

Assim, a disposição de enfrentar os problemas de suas vidas de frente ofereceu condições - não planejadas para a formação de uma cultura que corria paralela à cultura consensual. A 
linguagem cifrada para a grande parte do público, a moda que obrigatoriamente carrega os signos do gueto e o gestual agressivo, criou uma rejeição generalizada e muitas vezes intolerante contra a música rap. A pecha de música selvagem, maluca, baderna que comprova a ausência de cultura não conseguiu, todavia, neutralizar a disposição dos jovens periféricos de seguir adiante em busca de um status social diferenciado para suas vidas. Com essa determinação fizeram do rap um dos gêneros de música popular que mais se desenvolve atualmente. Alcançou esse status, por mais paradoxal que possa parecer, desafiando algumas das convenções estéticas mais incutidas da contemporaneidade.

\section{Referências}

ARISTÓTELES. Poética. Trad. de Eudoro de Souza, $2^{a}$ ed., São Paulo: Ars Poética, 1993.

CASTELLS, Manuel. $O$ poder $d a$ identidade. $3^{\mathrm{a}}$. São Paulo: Paz e Terra, 2002.

HALL, Stuart. A Identidade Cultural na Pós-modernidade. Rio de Janeiro: DP\&A, 1999.
HERSCHMANN, Michel (org.). Abalando os anos 90: globalização, violência e estilo cultural. Rio de Janeiro: Rocco, 1997.

MARCUSE, Herbert. A ideologia da sociedade industrial. Rio de Janeiro: Zahar, 1982.

MOISÉS, Massaud. Dicionário de termos literários, $16^{\mathrm{a}}$ ed., rev. E aum., São Paulo: cultrix, 2005.

PAZ, Octavio. O arco e a lira. Trad. bras. Rio de Janeiro: Nova Fronteira, 1982.

ROCHA, João Cezar de Castro. "Dialética da marginalidade, caracterização da cultura brasileira contemporânea". In: Folha de S. Paulo - Caderno Mais, 29 de fevereiro de 2004.

SHUSTERMAN, Richard. Vivendo a arte: o pensamento pragmatista $e$ a estética popular. São Paulo: Editora 34, 1998.

SOUSA, Rafael Lopes de. O movimento hip hop: a anti-cordialidade $d a$ "República dos Manos" e a estética da 
violência. São Paulo,

Annablume/Fapesp, 2012.

YÚDICE George. "A funkificação do

Rio". In: HERSCHMANN, M. (org).

Abalando os Anos 90: funk e hip-hop.

Globalização, violência e estilo

cultural. Rio de Janeiro: Rocco, 1997.

\footnotetext{
${ }^{1}$ Empregamos o termo anti-cordial a partir das sugestões de (HERSCHMANN, 1997:54) para quem o mito de origem da sociedade brasileira, isto é, "o mito das três raças" e do entendimento social caminham lado a lado com a cultura conciliatória do "Brasil Cordial". Conforme suas análises, essas representações orientaram, por muito tempo, o comportamento do indivíduo em sociedade, mas foram suplantadas no Brasil contemporâneo pela "cultura do medo e da violência". Para obter mais detalhes sobre as

${ }^{2}$ Entre os romances mais conhecidos de Ferrez estão: "Manual Prático do Ódio" e "Capão Pecado".
} 